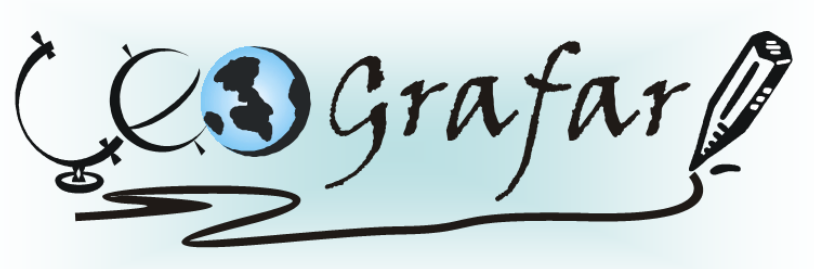

Revista Eletrônica do Programa de Pós-Graduação em Geografia - UFPR

\title{
O DESENVOLVIMENTO HUMANO NOS MUNICÍPIOS DA MESORREGIÃO NOROESTE PARANAENSE
}

\section{THE HUMAN DEVELOPMENT IN THE MUNICIPALITIES OF NORTHWEST PARANÁ STATE REGION}

\section{(Recebido em 26.03.2014; Aceito em: 14.06.2014)}

Luiz Henrique Paloschi Tomé

Mestrando em Desenvolvimento

Regional e Agronegócio Universidade Estadual do Oeste do Paraná

Toledo, PR, Brasil

e-mail: luiz.economista@hotmail.com

Jandir Ferrera de Lima

Prof. Dr. do PPG em Desenvolvimento

Regional e Agronegócio

Universidade Estadual do Oeste do Paraná

Toledo, PR, Brasil

e-mail: jandir.lima@unioeste.br

\begin{abstract}
RESUMO
O presente artigo analisa o desempenho do Índice de Desenvolvimento Humano Municipal (IDHM) nos municípios que fazem parte da mesorregião Noroeste Paranaense entre 2000 e 2010. A análise utiliza o IDHM estimado pelo Programa das Nações Unidas para o Desenvolvimento (PNUD). Optou-se pela região Noroeste Paranaense, como objeto dessa análise, devido ao fato dela situar-se entre as mais pobres do Paraná, além de compor a "área estendida", caracterizada pelo Instituto Paranaense de Desenvolvimento Econômico e Social (IPARDES), como a área que apresenta um conjunto de indicadores de desenvolvimento socioeconômico entre os piores do Estado do Paraná. A pesquisa fez comparativos sobre os resultados do IDHM tanto para os municípios quanto para as microrregiões. Os resultados demonstraram que o conjunto das mesorregiões do Paraná apresentou IDH abaixo de 0,80 , considerado indicador de forte desenvolvimento. No caso do Noroeste Paranaense, as microrregiões Paranavaí, Umuarama e Cianorte elevaram seus índices de desenvolvimento humano, saindo da condição de médio para alto.
\end{abstract}


Quando comparadas as mesorregiões do Paraná, constatou-se que as três regiões com maior índice de desenvolvimento também eram as com maior crescimento econômico. Na região Noroeste, embora não tenha seguido o padrão de maior crescimento econômico, mais Desenvolvimento Humano em 2010, o IDH calculado para as suas regiões acompanhou a evolução da concentração do Produto Interno Bruto. As regiões do Noroeste do Paraná que apresentaram maior crescimento no IDH também foram as que tiveram maior elevação no crescimento econômico, evidenciando uma forte influência do crescimento econômico no desenvolvimento dessas regiões.

Palavras-chave: Desenvolvimento Humano. Geografia Humana. Economia Urbana. Economia Paranaense.

\section{ABSTRACT}

This paper analyzes the performance of the Municipal Human Development Index (IDHM) of the municipalities that make up the Northwest Paraná State region between 2000 and 2010. The analysis uses the IDHM estimated by the United Nations Program for Development (UNDP). We opted for the Northwest region Paraná State, as the object of this analysis, due to the fact it is situated among the poorest of Paraná besides composing the "extended area" characterized by Paraná Institute of Economic and Social Development (IPARDES) as the area that presents a set of indicators of socioeconomic development among the worst in the Paraná State. The research done on the results of comparative IDHM both for municipalities and for their regions. The results showed that all the regions of Paraná State presented IDHM below 0.80 , an indicator of strong development. In the case of Northwest Paraná State, the Paranavaí, Umuarama and Cianorte regions and increased their human development indices, leaving the condition medium to high. Comparing the Paraná State regions, it was found that the regions with the highest development were also of higher economic growth. In the Northwest Paraná State, although it has not followed the pattern of higher economic growth, higher Human Development in 2010, the IDHM calculated for their regions monitored the concentration of the Gross Domestic Product. The regions of Northwest Paraná State showed that growth in IDHM were also those who had higher elevation economic growth, showing a strong influence of economic growth in the development of these regions.

Keywords: Human Development. Human Geography. Urban Economy. Paraná State Economy.

\section{INTRODUÇÃO}

Esse artigo analisa o comportamento do Índice de Desenvolvimento Humano Municipal (IDHM), estimado pelo Programa das Nações Unidas para o Desenvolvimento - PNUD (2013). O objeto da análise são os sessenta e um 
municípios que compõem a mesorregião Noroeste Paranaense, entre 2000 e 2010. Também foi feita a análise do IDHM de forma agregada, considerando as três microrregiões inseridas na mesorregião supra citada - Paranavaí, Umuarama e Cianorte - e da mesorregião Noroeste como um todo.

A escolha do Noroeste Paranaense, como objeto dessa análise, não foi aleatória. Essa mesorregião está entre as mais pobres do Paraná, no comparativo com outras mesorregiões paranaenses. Além disso, integra a "área estendida", caracterizada pelo Instituto Paranaense de Desenvolvimento Econômico e Social IPARDES (2014), como uma área cujos municípios possuem um conjunto de indicadores de desenvolvimento socioeconômico entre os mais baixos do Estado do Paraná.

Apesar dessa caracterização do Noroeste Paranaense, a mesorregião apresentou expansão na demanda por emprego industrial e serviços nos últimos anos. Ou seja, no computo geral, os dados de crescimento econômico são promissores. Por isso, cabe o questionamento: A mesorregião Noroeste Paranaense melhorou sua qualidade de vida? Houve melhorias nos indicadores de desenvolvimento humano? Para responder esses questionamentos, foi feita a análise do Índice de Desenvolvimento Humano Municipal no início do século XXI, para o período de 2000 e 2010. A partir do IDHM municipal foi feita a média ponderada $^{1}$ pela população para 0 conjunto das mesorregiões e microrregiões paranaenses, e com isso, comparar a situação do Noroeste Paranaense com as outras mesorregiões do Estado do Paraná, bem como, cotejar as microrregiões inseridas no Noroeste Paranaense.

Cabe ressaltar que esse texto faz apenas uma análise descritiva e o estudo comparativo dos resultados do IDH-M a partir de dados secundários. A análise não se aprofunda nos elementos e fatores que levaram ao perfil de atraso do IDH-M no inicio do período estudado. Porém, a literatura paranaense, capitaneada pelas pesquisas do Instituto Paranaense de Desenvolvimento Econômico e Social (IPARDES) e das Instituições de Ensino Superior do Paraná é rica em análises que

\footnotetext{
${ }^{1} W=\frac{\sum_{i=1}^{n} X_{i} q_{i}}{\sum_{i=1}^{2} q_{i}}$ em que $W$ é o IDH para a microrregião ou mesorregião analisada, $x_{i}$ é o IDHM no município $\dot{i}$ e $q_{\mathrm{i}}$ é a população desse município, utilizada como fator de ponderação. Portanto, $W$ é o somatório do produto entre o IDHM e a população dos municípios que compõem a região analisada dividido pelo somatório da população dos respectivos municípios.
} 
podem ajudar o leitor mais arguto sobre o processo histórico de desenvolvimento do Noroeste paranaense.

O texto está dividido em quatro seções, além dessa introdução: na sequência é feita uma releitura da teoria do capital humano; em seguida são apresentados os indicadores de desenvolvimento humano para o Paraná e suas mesorregiões. Por fim, é feita uma análise do IDHM nos municípios e nas microrregiões que fazem parte do Noroeste Paranaense. A conclusão finaliza essa análise.

\section{O CAPITAL HUMANO E O DESENVOLVIMENTO HUMANO: BREVE REVISÃO DE LITERATURA}

A economia clássica, advinda das ideias de Adam Smith e David Ricardo, no final do século XVIII e início do século XIX, marcou a ideia difundida até o final da década de 1940 que a dotação de fatores produtivos como recursos naturais, trabalho e capital determinava o crescimento econômico de um país ou região, ou seja, quanto maior a disponibilidade e otimização desses fatores maior o crescimento econômico. Além disso, o processo de desenvolvimento econômico seria uma consequência automática do processo de crescimento econômico. E essa ideia valia tanto para regiões ricas quanto para as regiões pobres.

O erro dos pensadores clássicos foi considerar que a teoria econômica não se ajustava aos problemas de regiões pobres. Considerando que a maioria da população mundial é pobre, então é lógica a necessidade de se analisar justamente os problemas de capital humano para entender os determinantes do crescimento e do desenvolvimento econômico de forma mais completa. Assim, os principais fatores promotores do crescimento da produção e do avanço do bem-estar da população de baixa renda não é a quantidade de capitais físicos, e sim a melhoria da qualidade da população e os avanços no conhecimento (SCHULTZ, 1987).

A pobreza é uma condição que pode ser mudada com investimentos em saúde e educação, sendo este último o fator de maior importância para a melhoria na qualidade da população. Os gastos em educação devem ser encarados, não como simples despesas no consumo de bens e serviços, mas, como um investimento no estoque de profissionais com conhecimentos e maiores 
capacidades produtivas. Assim, os investimentos em educação possibilitarão às regiões um crescimento no número de técnicos e profissionais de diferentes especialidades, voltados para a produção, pesquisa, desenvolvimento e inovação nas mais diferentes áreas. Os investimentos em capital humano contribuirão tanto para o crescimento econômico quanto para o desenvolvimento humano, com maiores rendas, maior produtividade da mão de obra, e melhor qualidade de vida (SCHULTZ, 1987).

A visão de Schultz (1987) é diferente de Dumais et all. (2005), que apontam dois elementos como norteadores do crescimento e do desenvolvimento econômico: as empresas, com suas potencialidades e inovações; e, o Estado, como agente indutor. Porém, os autores esqueceram que o componente humano tem um papel crucial no processo de crescimento e desenvolvimento econômico, tanto do lado das empresas ao estimularem o crescimento da produtividade e criarem inovações, quanto do lado do Estado, ao influenciarem politicamente as diretivas da intervenção estatal.

Tendo em mente os obstáculos à difusão espacial do crescimento, o Estado não deve negligenciar as necessidades que emergem das aglomerações. O Estado tem o poder de facilitar a concentração da produção, ou de beneficiar a população com a oferta de serviços como educação, segurança, saúde, etc. (SANTOS, 2003). O papel do Estado enquanto responsável pela melhoria dos indicadores sociais demonstra que o desenvolvimento econômico não é apenas a produção e a distribuição, mas a garantia de níveis de vida, que se refletem nos indicadores sociais, tais como: educação e longevidade. $O$ desenvolvimento econômico é um processo complexo que não depende apenas de fatores econômicos, mas também de muitos aspectos relacionados a vida das pessoas (MYRDAL, 1977).

Os estudos de Sen $(2000 ; 2001)$ convergem para as concepções de Myrdal (1977). Para Sen $(2000 ; 2001)$, o desenvolvimento econômico é o resultado da competição e da seleção entre os indivíduos. Para conquistar mais mercados, por vezes as pessoas sacrificam o bem-estar imediato, o meio ambiente e a solidariedade. Porém, o desenvolvimento econômico também é possível quando a sociedade avança na solidariedade. Por isso, o desenvolvimento é definido como um processo através do qual vão sendo obtidas cada vez mais melhorias no nível de vida. 
O desenvolvimento econômico refere-se a mudanças tanto quantitativas como qualitativas, relacionadas à elevação do produto, dos investimentos, da renda, do emprego, redução das disparidades sociais, melhor distribuição dos recursos, melhores condições de vida à população, avanços tecnológicos, entre outros fatores que culminam na elevação do nível de liberdade da sociedade (SEN, 2000).

Já Sachs (2002) enfatiza o papel da geografia, dos sistemas sociais e da rentabilidade dos investimentos e inovações como elementos norteadores do crescimento econômico e do progresso social. Se esses elementos não são estimulados ou favoráveis aos avanços nos capitais intangíveis preconizados por Haddad (2009), o processo de desenvolvimento socioeconômico será desigual e com assimetrias expressivas entre as classes sociais. Para os autores, conhecer o avanço no desenvolvimento das regiões implica em mensurar aspectos sociais e econômicos, criticando a visão tradicional que o crescimento econômico conduz necessariamente ao desenvolvimento econômico.

Outra crítica a visão tradicional do desenvolvimento econômico apenas como melhora nos indicadores de crescimento econômico é de Sobrinho (2001). Para o autor, uma região pobre que consiga avançar em melhoria nos seus indicadores de saúde e educação pode ter rebatimentos positivos no crescimento econômico. Tanto que a questão educacional é a principal limitadora nos avanços das melhorias na renda. O Estado, por meio da política pública deve criar oportunidades sociais para que se possibilite a melhoria nos indicadores de desenvolvimento humano e se fortaleça o papel das pessoas no processo de expansão econômica.

Da mesma forma, considerando o Estado como uma instituição, e reconhecendo que, assim como as regiões, as instituições não são neutras no processo de desenvolvimento socioeconômico, salienta a importância de analisar o papel das instituições nos territórios para entender as disparidades regionais e as mudanças na dinâmica do desenvolvimento. As instituições exercem influências na distribuição de recursos econômicos, sociais e territoriais, podendo atuar no incentivo à criação de distritos industriais, redes de inovação e externalidades positivas (FERRERA DE LIMA, 2012). 


\section{O IDH NO CONJUNTO DO ESTADO DO PARANÁ}

Considerando os dados de 2000, o ranking da média do IDH entre as dez mesorregiões paranaenses se apresentava da seguinte forma: Metropolitana de Curitiba $(0,6843)$, Norte Central $(0,6677)$, Oeste $(0,6595)$, Sudoeste $(0,6327)$, Centro Oriental $(0,6283)$, Noroeste $(0,6268)$, Centro Ocidental $(0,6088)$, Norte Pioneiro $(0,6068)$, Sudeste $(0,5697)$ e Centro-Sul $(0,5620)$. Ou seja, o conjunto das mesorregiões do Paraná apresentou o IDH abaixo de 0,70 (alto desenvolvimento), sendo que, duas mesorregiões estão na faixa de desenvolvimento baixo $(0,500 \mathrm{a}$ $0,599)$ e as demais apresentaram desenvolvimento médio $(0,600$ a 0,699$)$.

Além disso, o IDH acompanhava a tendência de concentração do Produto Interno Bruto (PIB), como pode ser visto na Tabela 1, que apresenta os valores do PIB das mesorregiões paranaenses e suas respectivas participações percentuais no total do Paraná. Em 2000, as mesorregiões Metropolitana de Curitiba, Norte Central e Oeste paranaense, que detinham os três maiores índices de desenvolvimento humano neste ano, participaram com 44,88\%, 16,87\% e 12,44\% do PIB paranaense, respectivamente, sendo também as com maior participação no PIB.

Tabela 1 - Participação das mesorregiões no Produto Interno Bruto do Paraná - 2000 e 2010.

\begin{tabular}{|c|c|c|c|c|c|c|}
\hline & \multicolumn{2}{|c|}{2000} & \multicolumn{2}{|c|}{2010} & \multirow{2}{*}{\begin{tabular}{|c|} 
Variação do \\
PIB
\end{tabular}} & \multirow{2}{*}{$\begin{array}{l}\text { Variação da } \\
\text { participação }\end{array}$} \\
\hline & PIB $^{1}$ & Participação & PIB $^{1}$ & Participação & & \\
\hline Paraná & $158.695 .906,56$ & $100,00 \%$ & $252.948 .069,28$ & $100,00 \%$ & $59,39 \%$ & $0,00 \%$ \\
\hline \multicolumn{7}{|l|}{ Mesorregiões } \\
\hline Centro-Ocidental & $4.476 .820,50$ & $2,82 \%$ & $6.001 .657,96$ & $2,37 \%$ & $34,06 \%$ & $-15,89 \%$ \\
\hline Centro-Oriental & $9.679 .236,03$ & $6,10 \%$ & $14.695 .214,04$ & $5,81 \%$ & $51,82 \%$ & $-4,75 \%$ \\
\hline Centro-Sul & $5.016 .442,81$ & $3,16 \%$ & 7.098.707,33 & $2,81 \%$ & $41,51 \%$ & $-11,22 \%$ \\
\hline Metr. de Curitiba & $71.225 .751,29$ & $44,88 \%$ & $120.601 .329,87$ & $47,68 \%$ & $69,32 \%$ & $6,23 \%$ \\
\hline Noroeste & $6.290 .018,40$ & $3,96 \%$ & $11.089 .523,50$ & $4,38 \%$ & $76,30 \%$ & $10,61 \%$ \\
\hline Norte Central & $26.777 .985,58$ & $16,87 \%$ & $40.808 .108,21$ & $16,13 \%$ & $52,39 \%$ & $-4,39 \%$ \\
\hline Norte Pioneiro & $5.141 .961,14$ & $3,24 \%$ & $7.764 .930,63$ & $3,07 \%$ & $51,01 \%$ & $-5,26 \%$ \\
\hline Oeste & $19.743 .920,18$ & $12,44 \%$ & $28.462 .156,52$ & $11,25 \%$ & $44,16 \%$ & $-9,56 \%$ \\
\hline Sudeste & $3.578 .681,95$ & $2,26 \%$ & $5.415 .676,44$ & $2,14 \%$ & $51,33 \%$ & $-5,06 \%$ \\
\hline Sudoeste & $6.765 .088,69$ & $4,26 \%$ & $11.010 .764,79$ & $4,35 \%$ & $62,76 \%$ & $2,11 \%$ \\
\hline
\end{tabular}

Fonte: IPARDES (2014).

${ }^{1}$ A preços de Agosto de 2013, atualizados pelo Índice Nacional de Preços ao Consumidor (INPC). 
Em 2010, a composição do ranking manteve-se inalterada, porém com melhorias no IDH em todas as mesorregiões, como segue: Metropolitana de Curitiba $(0,7737)$, Norte Central $(0,7511)$, Oeste $(0,7490)$, Sudoeste $(0,7366)$, Centro Oriental $(0,7269)$, Noroeste $(0,7256)$, Centro Ocidental $(0,7202)$, Norte Pioneiro $(0,7110)$, Sudeste $(0,6910)$ e Centro-Sul $(0,6823)$. Mesmo assim, o IDH continua abaixo de 0,80 apesar da melhoria significativa dos indicadores no conjunto das mesorregiões.

Também em 2010, o IDH seguiu a tendência de concentração do Produto Interno Bruto. As mesorregiões Metropolitana de Curitiba, Norte Central e Oeste paranaense, com os três maiores índices de desenvolvimento humano neste ano, participaram com $47,68 \%, 16,13 \%$ e $11,25 \%$ do PIB estadual, respectivamente.

Analisando a participação das mesorregiões paranaenses no PIB total do Estado, apenas três elevaram suas participações de 2000 para 2010: a Noroeste, que saiu de 3,96\% para 4,38\%; a Metropolitana de Curitiba, passando de 44,88\% para $47,68 \%$; e a Sudoeste, de $4,26 \%$ para $4,35 \%$. Os números do crescimento do PIB nessas regiões corroboram para esse resultado: a mesorregião Noroeste obteve o maior crescimento percentual do Produto Interno Bruto no período $(76,30 \%)$, com uma taxa geométrica média de crescimento de $5,83 \%$ a.a. (significativo a $1 \%$ ), seguida pela Região Metropolitana de Curitiba (RMC), com elevação de 69,32\% no PIB e taxa geométrica média de crescimento de $5,70 \%$ a.a. (significativo a $1 \%$ ), e pela Sudoeste, com crescimento de $62,76 \%$ e taxa geométrica média de crescimento de $5,13 \%$ ao ano. (significativo a $1 \%$ ).

Os dados do crescimento econômico da mesorregião Noroeste Paranaense confirmam seu destaque entre as demais mesorregiões do Estado, reforçando os questionamentos levantados na introdução e a importância em analisar se os efeitos desse crescimento contribuem positivamente para o desenvolvimento da região. Dessa forma, a próxima seção analisa com mais detalhes a evolução do Índice de Desenvolvimento Humano nos municípios e microrregiões que compõem o Noroeste Paranaense.

\section{O NOROESTE PARANAENSE: A EVOLUÇÃO DO IDH MUNICIPAL}

No caso do Noroeste Paranaense, o IDH estimado passou de 0,6268 para 0,7256, apresentando um crescimento absoluto no índice no valor de 0,0988 ou 
$15,76 \%$. O indicador saiu da faixa de desenvolvimento humano médio $(0,600$ a $0,699)$ passando para alto $(0,700$ a 0,799$)$, embora tenha permanecido em sexto lugar entre as dez mesorregiões paranaenses.

Os dados da Figura 01 mostram que em 2000 o componente mais significativo do IDH na mesorregião foi a longevidade com índice de 0,7641 , seguido pela renda $(0,6471)$ e pela educação $(0,4995)$. Já os dados de 2010 mostraram que todos os componentes avançaram, embora tenham mantido a mesma composição, uma vez que longevidade assumiu maior índice $(0,8275)$ seguida pela renda $(0,7146)$ e educação $(0,6470)$. A dimensão que apresentou maior crescimento absoluto entre 2000 e 2010 foi a educação com incremento de 0,1475 , seguida pela renda (aumento de 0,0675) e longevidade (crescimento de 0,0634). De um lado, o melhor indicador é a longevidade da população, o que demonstra melhorias nas condições de vida e saúde, porém a educação e renda tiveram melhorias sensíveis. A longevidade também está atrelada a educação e renda, pois ela depende de melhores condições de acesso aos bens de consumo e da mesma maneira a ações preventivas de saúde.

Frente a esses resultados cabe resgatar Schultz (1987), para o qual os investimentos em saúde e educação têm reflexo direto na qualidade de vida da população. Ou seja, a melhoria dos indicadores reflete o impacto positivo das despesas governamentais e da ação das organizações responsáveis pela saúde e educação, mas também a melhoria no perfil do capital humano. Considerando o mercado de trabalho, houve também uma melhoria no estoque de profissionais com conhecimentos e maiores capacidades produtivas. 
Figura 01 - Índice de Desenvolvimento Humano da mesorregião Noroeste Paranaense 2000 e 2010.

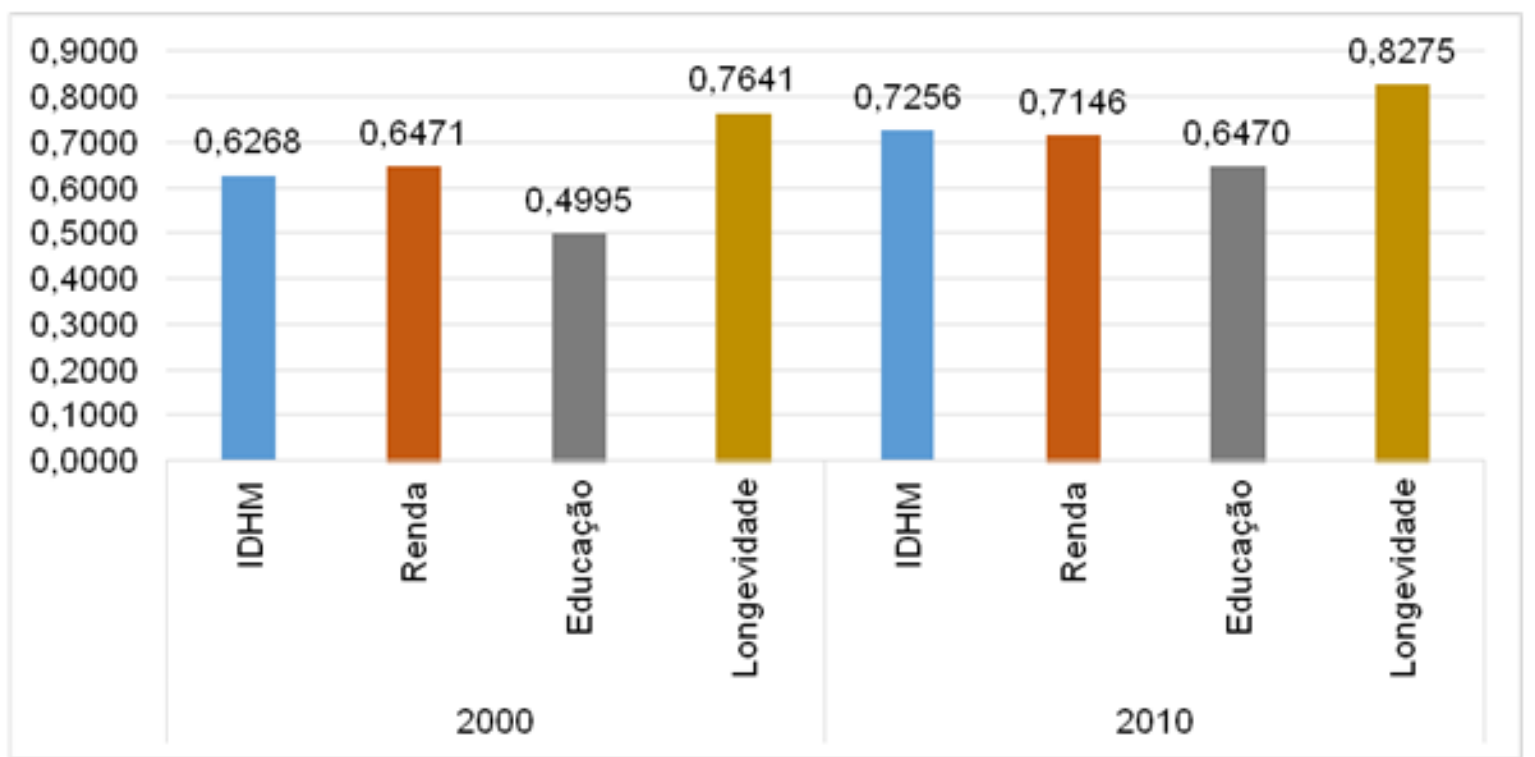

Fonte: calculado a partir de dados do PNUD (2013).

Analisando as microrregiões paranaenses - Paranavaí, Umuarama e Cianorte - que fazem parte da mesorregião Noroeste, se percebe que a microrregião Paranavaí tinha o maior IDH em 2000 (0,6333), mas passou para o segundo lugar em 2010 com um índice de 0,7258 (variação de 0,0925). Também houve crescimento em todos os subíndices e a composição em 2010 manteve-se, assim como em 2000, com a longevidade como maior índice $(0,8302)$, seguido por renda $(0,7108)$ e educação $(0,6488)$. A educação foi o componente que mais cresceu de 2000 à 2010, com elevação absoluta de 0,1362, acompanhada pela renda (aumento de 0,0655) e pela longevidade (expansão de 0,0606).

Umuarama, que ocupava a segunda posição em 2000, com IDH de 0,6241, caiu para a terceira em 2010, com 0,7215 (crescimento de 0,0974). Em 2010, a longevidade foi o componente com maior índice $(0,8237)$, enquanto renda e educação apresentaram 0,7136 e 0,6401, respectivamente. $O$ componente que mais cresceu no período foi a educação, com elevação de 0,1445 , seguida pela renda (incremento de 0,0698) e longevidade (elevação de 0,0594).

Já Cianorte, que em 2000 era a terceira colocada entre as microrregiões, com 0,6193, assumiu a primeira posição em 2010, com 0,7331. Em 2010, a longevidade, assim como nas demais microrregiões, foi a dimensão com maior índice $(0,8296)$, acompanhada pela renda $(0,7238)$ e educação $(0,6564)$. Dentre os subíndices, a educação foi o que mais cresceu (aumento de 0,1760) seguido por 
longevidade $(0,0772)$ e renda $(0,0663)$. Cianorte apresentou ainda maior avanço do IDH de 2000 à 2010, com uma elevação de 0,1139 (18,39\%), seguida por Umuarama $(0,0974)$ e Paranavaí $(0,0925)$, corroborando para sua mudança de posição no período.

Vale ressaltar que as microrregiões Paranavaí, Umuarama e Cianorte, que compõem a mesorregião Noroeste Paranaense, elevaram seus índices de desenvolvimento, saindo da condição de médio para alto, como pode ser visualizado na Tabela 2.

Tabela 2 - Índice de Desenvolvimento Humano das microrregiões inseridas na mesorregião Noroeste Paranaense - 2000 e 2010.

\begin{tabular}{l|l|lll|l|lcl}
\hline & \multicolumn{3}{|c|}{2000} & \multicolumn{4}{c}{2010} \\
\cline { 2 - 9 } & IDHM & Renda & Educação & Longevidade & IDHM & Renda & Educação & Longevidade \\
\hline Paranavaí & 0,6333 & 0,6454 & 0,5126 & 0,7696 & 0,7258 & 0,7108 & 0,6488 & 0,8302 \\
\hline Umuarama & 0,6241 & 0,6439 & 0,4956 & 0,7643 & 0,7215 & 0,7136 & 0,6401 & 0,8237 \\
\hline Cianorte & 0,6193 & 0,6575 & 0,4803 & 0,7524 & 0,7331 & 0,7238 & 0,6564 & 0,8296 \\
\hline
\end{tabular}

Fonte: calculado a partir de dados do PNUD (2013).

Dentre as sessenta e uma cidades que compõem a mesorregião Noroeste Paranaense, merecem destaque as que apresentaram maior IDHM em 2010, a saber: Paranavaí $(0,7630)$ e Umuarama $(0,7610)$. Paranavaí, em 2000, já era o município com maior índice da mesorregião com 0,6920, enquanto Umuarama com índice de 0,6800 ocupava a terceira posição. Nos dois municípios destacados, a longevidade foi a dimensão com maior índice, seguida por renda e educação. De forma contrária, Mariluz se destacou como o município com o menor IDHM da região, com índice de 0,6390, logo depois de Itaúna do Sul com 0,6560.

Com relação a composição do IDHM dos municípios, a maioria deles apresentaram, em 2000, a longevidade como a dimensão com maior índice, seguida por renda e educação, composição essa que foi mantida em 2010. Somente o município de Nova Aliança do Ivaí tem uma configuração diferente, tanto em 2000 como 2010, com longevidade em primeiro, educação em segundo e renda por último. Outrossim, a dimensão educação foi o subíndice que mais cresceu no período para cinquenta e oito municípios. Apenas para três municípios a renda foi a dimensão que apresentou maior elevação, são eles, São Jorge do Patrocínio, Jussara e São Manoel do Paraná. 
Considerando a evolução do Índice de Desenvolvimento Humano Municipal de 2000 à 2010, Guaporema e Inajá foram os municípios que apresentaram maior crescimento absoluto, a primeira saiu de 0,5630 para 0,7190 (incremento de 0,1560 ) e a segunda de 0,5540 para 0,7050 (aumento de 0,1510). Já as que menos cresceram foram Icaraíma e Nova Aliança do Ivaí, com expansão de 0,0560 e 0,0610, respectivamente.

A distribuição dos municípios que compõem a Mesorregião Noroeste Paranaense pode ser visualizada na Figura 02, com o mapa da mesorregião e a indicação dos municípios.

Figura 02 - Municípios que compõem a Mesorregião Noroeste Paranaense

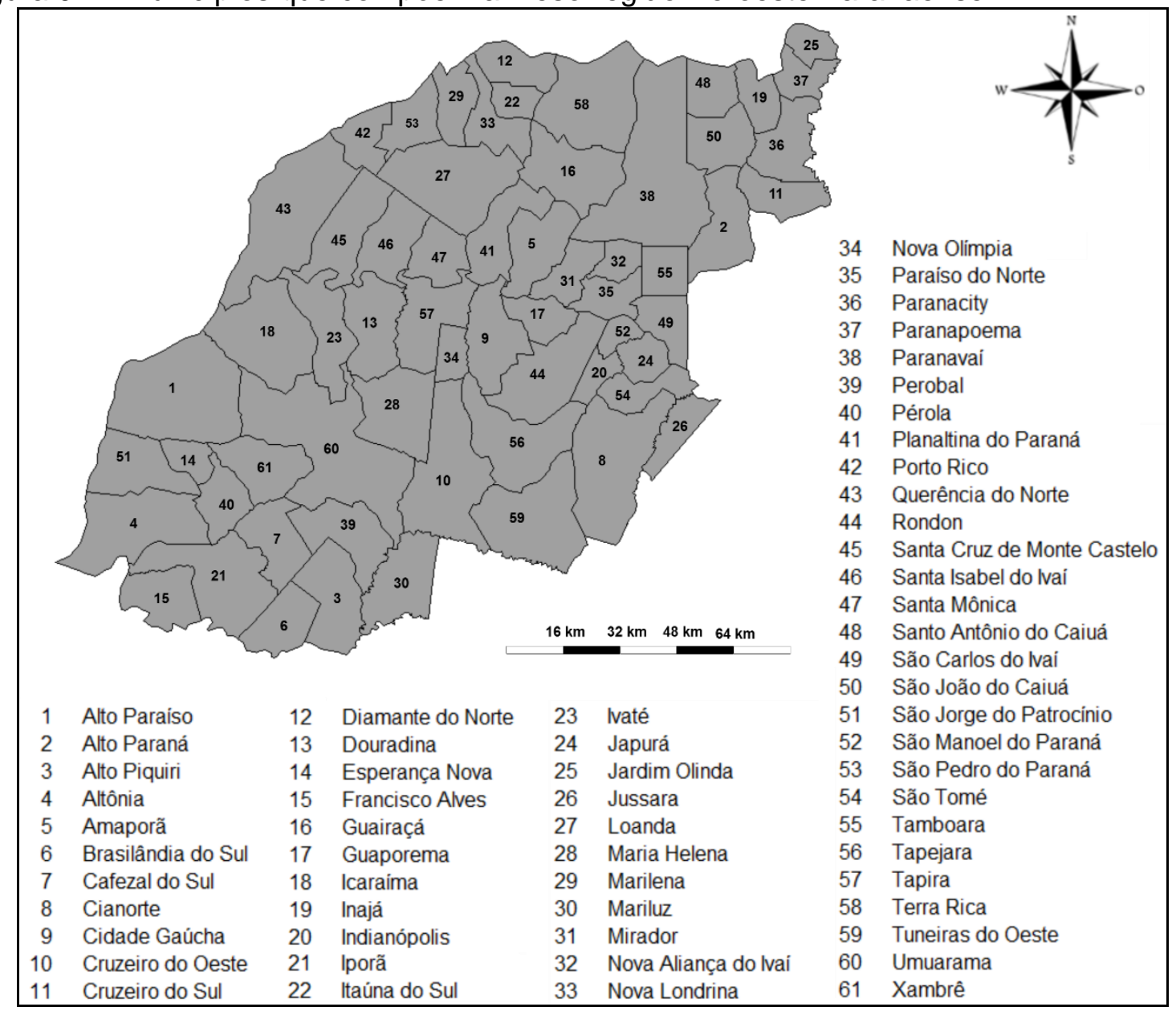

Fonte: elaborado a partir de dados do IPARDES (2014).

A Figura 03 apresenta a mesorregião Noroeste Paranaense e os resultados da distribuição espacial do Índice de Desenvolvimento Humano Municipal. Na Figura nota-se claramente o avanço no IDHM dos municípios entre 2000 e 2010. A imagem referente a 2000 é predominantemente composta por cores claras, que indicam 
baixo desenvolvimento (IDHM entre 0,500 e 0,599), neste ano 31 municípios tiveram índices entre 0,500 e 0,599, e, os outros 30 apresentaram índices entre 0,600 e 0,699 (médio desenvolvimento). Já em 2010, a imagem é mais escura, apontando para índices de desenvolvimento maiores, neste ano nenhum município apresentou índices abaixo de 0,600, enquanto que 22 municípios apresentaram índices entre 0,600 e 0,699, e, 39 tiveram índices entre 0,700 e 0,799. Ou seja, ao longo do tempo houve uma melhoria significativa nas condições de vida da produção da mesorregião Noroeste Paranaense.

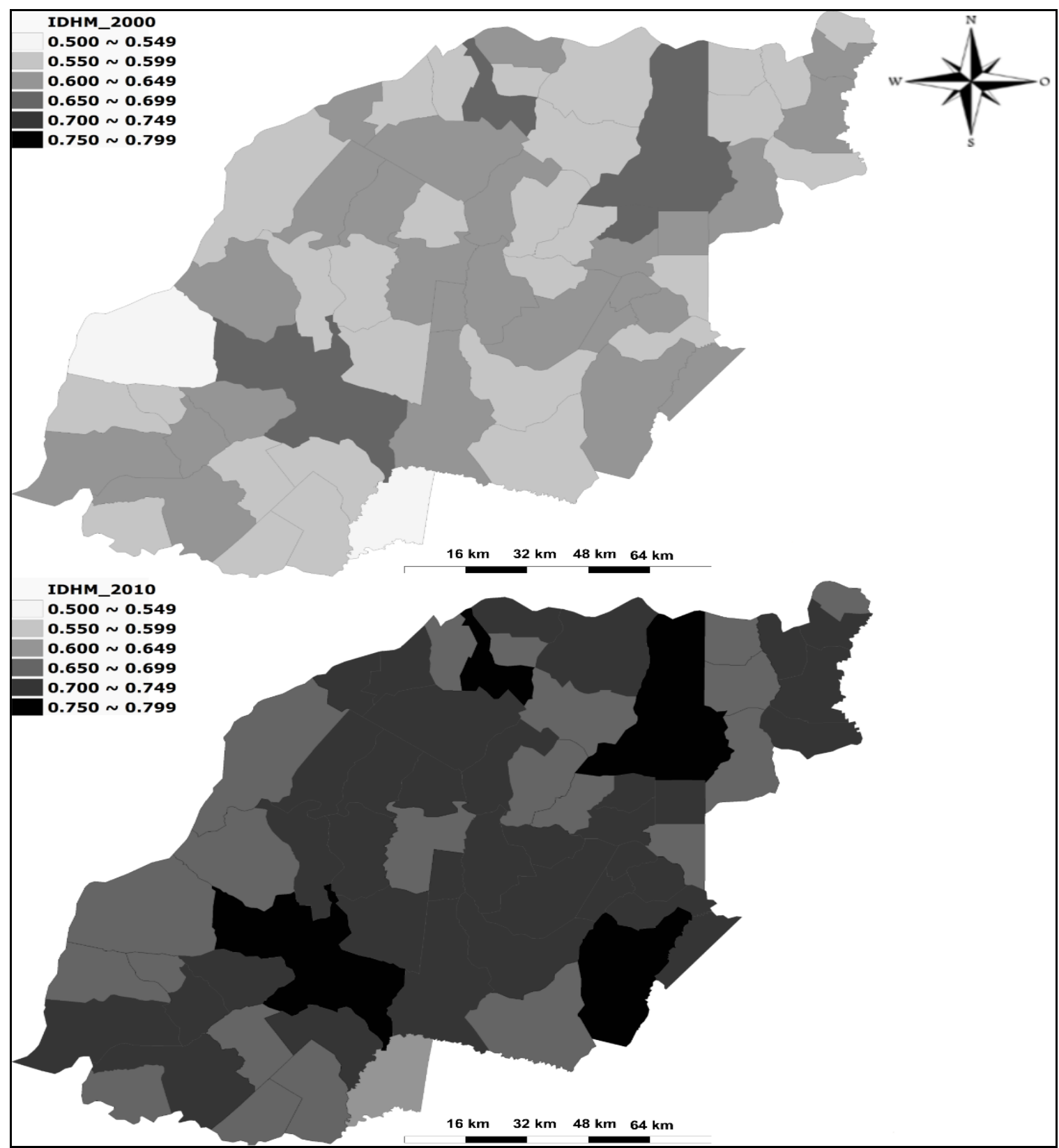

Figura 03 - Índice de Desenvolvimento Humano dos municípios inseridos na mesorregião Noroeste Paranaense - 2000 e 2010. Fonte: elaborado a partir de dados do PNUD (2013). 
Ademais, o IDH no Noroeste Paranaense acompanha a evolução da concentração do PIB como pode ser visto na Tabela 3, com os valores do PIB das microrregiões e suas respectivas participações percentuais no total da mesorregião. A microrregião de Cianorte, que tinha o terceiro IDH da mesorregião em $2000 \mathrm{e}$ passou para o primeiro em 2010 , foi a que mais elevou seu PIB no período $(97,50 \%$ de elevação), com uma taxa geométrica média de crescimento de $7,30 \%$ a.a. (significativo a 1\%). Cianorte foi a única microrregião do Noroeste a aumentar sua participação de 2000 para 2010, saindo de 22,72\% para 25,45\% (variação de $12,03 \%)$.

Tabela 3 - Participação das microrregiões no Produto Interno Bruto do Noroeste Paranaense - 2000 e 2010.

\begin{tabular}{|c|c|c|c|c|c|c|}
\hline & \multirow{2}{*}{\multicolumn{2}{|c|}{2000}} & \multirow{2}{*}{\multicolumn{2}{|c|}{2010}} & \multirow{3}{*}{$\begin{array}{c}\text { Variação } \\
\text { do PIB }\end{array}$} & \multirow{3}{*}{$\begin{array}{l}\text { Variação da } \\
\text { participação }\end{array}$} \\
\hline & & & & & & \\
\hline & PIB1 & Participação & PIB1 & Participação & & \\
\hline Noroeste & $6.290 .018,40$ & $100,00 \%$ & $11.089 .523,50$ & $100,00 \%$ & $76,30 \%$ & $0,00 \%$ \\
\hline \multicolumn{7}{|c|}{ Microrregiões } \\
\hline Cianorte & $1.428 .959,57$ & $22,72 \%$ & $2.822 .258,13$ & $25,45 \%$ & $97,50 \%$ & $12,03 \%$ \\
\hline Paranavaí & $2.359 .463,66$ & $37,51 \%$ & $3.982 .032,99$ & $35,91 \%$ & $68,77 \%$ & $-4,27 \%$ \\
\hline Umuarama & $2.501 .595,18$ & $39,77 \%$ & $4.285 .232,37$ & $38,64 \%$ & $71,30 \%$ & $-2,84 \%$ \\
\hline
\end{tabular}

Fonte: IPARDES (2014).

'A preços de Agosto de 2013, atualizados pelo Índice Nacional de Preços ao Consumidor (INPC).

Mesmo Paranavaí tendo um crescimento de $68,77 \%$ no PIB no período, com uma taxa geométrica média de crescimento de 5,24\% ao ano. (significativo a $1 \%$ ), sua participação caiu de 37,51\% em 2000 para 35,91\% em 2010. O mesmo ocorreu com Umuarama que apresentou elevação de $71,30 \%$ no Produto Interno Bruto, com taxa geométrica média de crescimento de $5,49 \%$ ao ano. (significativo a $1 \%$ ), e redução da participação de $39,77 \%$ para 38,64\%.

Para Schultz (1987), a melhoria nos indicadores sociais e a ampliação da cobertura dos gastos e acesso à saúde e educação seriam responsáveis pela melhoria dos estoques de profissionais, ou seja, de capital humano o que teria influência nos resultados econômicos. Para o autor, os investimentos em capital humano contribuem para o crescimento econômico e para o desenvolvimento humano. No caso da mesorregião objeto do estudo se percebe uma perda de participação da microrregião de Umuarama, apesar do seu município sede representar um centro polarizador na mesorregião. No caso de Cianorte, apesar do 
IDH-M renda ter crescido menos que longevidade e educação, houve melhorias na sua participação na riqueza regional.

Em contraste, ao se comparar os resultados da Figura 03 com a Tabela 03, se percebe que no conjunto a microrregião de Cianorte teve avanços significativos, tanto na melhoria do IDH quanto na participação do PIB. De certa forma, o aumento na participação do Noroeste no PIB estadual e o aumento da participação das microrregiões no PIB intrarregional demonstra o fortalecimento de áreas mais periféricas do Noroeste Paranaense. Isso é resultado tanto da evolução positiva dos sub índices do IDH ligados diretamente a educação e longevidade, quanto emprego e renda. No seu conjunto, a mesorregião conseguir não apenas melhorar a dispersão do desenvolvimento socioeconômico, quanto tornar mais difusa a distribuição do PIB.

Frente a essa realidade, o Noroeste paranaense obteve ganhos importantes na melhoria dos indicadores sociais. Quiçá esses ganhos se reflitam em ganhos mais significativos em termos de produção e ampliação do nível de emprego. Agora resta converter ganhos ligados a melhoria das condições de vida em ganhos também ligados a fatores econômicos, garantindo a manutenção do ritmo do crescimento econômico nos próximos anos.

\section{CONCLUSÃO}

Esse artigo analisou o comportamento do Índice de Desenvolvimento Humano Municipal (IDHM) dos municípios que compõem a mesorregião Noroeste Paranaense e das microrregiões inseridas nessa mesorregião entre 2000 e 2010.

O Índice de Desenvolvimento Humano Municipal (IDHM) utilizado foi o estimado pelo Programa das Nações Unidas para o Desenvolvimento (PNUD). A partir do IDHM municipal foi feita a média ponderada pela população para o conjunto das mesorregiões e microrregiões paranaenses. Esse procedimento foi utilizado para comparar a situação do Noroeste Paranaense com as outras mesorregiões do Estado do Paraná, bem como, cotejar as microrregiões inseridas no Noroeste Paranaense.

Os resultados demonstraram que o conjunto das mesorregiões do Paraná apresentou o IDH abaixo de 0,80, considerado indicador de forte desenvolvimento. 
No caso do Noroeste Paranaense, as microrregiões Paranavaí, Umuarama e Cianorte elevaram seus índices de desenvolvimento, saindo da condição de médio para alto, com destaque para Cianorte que em 2000 era a terceira colocada entre as microrregiões, com 0,6193; e, em 2010, assumiu a primeira posição, com 0,7331.

No caso dos municípios do Noroeste Paranaense, em 2010 os que apresentaram maior IDHM, foram: Paranavaí $(0,7630)$ e Umuarama $(0,7610)$. Paranavaí, em 2000, já era o município com maior índice da mesorregião com 0,6920, enquanto Umuarama com índice de 0,6800 ocupava a terceira posição. Nas duas cidades destacadas, a longevidade foi a dimensão com maior índice, seguida por renda e educação. De forma contrária, Mariluz foi o município com o menor IDHM da região, com índice de 0,6390, logo depois de Itaúna do Sul com 0,6560.

Um outro aspecto do comportamento do IDH na região chamou atenção. Quando comparadas as mesorregiões do Paraná, constatou-se que as três regiões com maior índice de desenvolvimento também eram as com maior PIB. $\mathrm{Na}$ mesorregião Noroeste, embora não tenha seguido o padrão maior PIB/maior IDH em 2010, o índice de desenvolvimento calculado para as microrregiões acompanhou a evolução da concentração do Produto Interno Bruto, ou seja, as microrregiões que apresentaram maior crescimento no IDH também foram as que tiveram maior elevação no PIB, evidenciando uma forte influência do crescimento econômico no desenvolvimento dessas regiões.

Pelos resultados da pesquisa e o comportamento dos sub-indicadores que compõem o IDHM se percebe que há dois elementos norteadores do desempenho das melhorias no desenvolvimento humano do Noroeste Paranaense: o crescimento econômico, capitaneado pelas condições de emprego e renda da população, cujas melhorias se percebeu de maneira patente; a ação do Estado, representado tanto em suas mais diversas esferas, cujos programas sociais e de saúde pública melhoraram as condições de vida da população rebatendo nos indicadores de longevidade.

Porém cabe um alerta: o Noroeste Paranaense precisa avançar mais em termos de desenvolvimento humano. Mais do que nunca as políticas públicas em escala municipal devem convergir para investimentos em educação e saúde de qualidade. No quesito renda, as melhorias na qualidade de vida serão elementos 
para garantir ganhos de produtividade e, consequentemente, melhoria nos ganhos tanto das empresas quanto dos cidadãos.

Por fim, cabe ressaltar que essa análise discute apenas dados secundários. Por isso, se faz necessários outros trabalhos que analisem com mais profundidade as condições e o perfil do desenvolvimento do Noroeste Paranaense. De certa forma, a analise demonstra que o Noroeste está em desenvolvimento, pois houveram melhorias nos seus indicadores o que demonstra uma tendência a reversão do empobrecimento da região. Se essa tendência for mantida e o Noroeste conseguir taxas de crescimento econômico acima da média paranaense, complementadas por melhorias no quadro de inclusão social, então com certeza a mesorregião figurará entre as mais desenvolvidas do Paraná para as próximas décadas.

\section{REFERÊNCIAS}

DUMAIS, S.; MALO, M-C.; RAEFFLET, E. Les liens d'interrelation et le dynamisme économique d'une MRC gaspésienne. Organisations et Territoires, Québec, vol. 14, no.1, p.79-86, 2005.

FERRERA DE LIMA, J. Géoéconomie et développement regional. Paris (França): Publibook, 2012.

INSTITUTO PARANAENSE DE DESENVOLVIMENTO ECONÔMICO E SOCIAL (IPARDES). Banco de dados estadual. Disponivel em: <http:www.ipardes.pr.gov.br>. Acesso em 14 fevereiro 2014.

MYRDAL, G. Contra a corrente: ensaios críticos em economia. Rio de Janeiro: Campus, 1977, p., 1977.

PROGRAMA DAS NAÇÕES UNIDAS PARA O DESENVOLVIMENTO (PNUD). Atlas do desenvolvimento humano no Brasil 2013. Disponível em: <http://atlasbrasil.org.br/2013/pt/download/>. Acesso em: 20 novembro 2013.

SACHS, J. Notas para uma nova sociologia do desenvolvimento econômico. In: HARRISON, L. E.; HUNTINGTON, S. (Org.) Cultura importa: os valores que definem o progresso humano. Rio de Janeiro: Record, p. 71-88, 2002.

SANTOS, M. Economia espacial: críticas e alternativas. 2 ed. São Paulo: Edusp, 2003. 
SEN, A. K. Desenvolvimento como liberdade. São Paulo: Companhia das Letras, 2000.

Desigualdade reexaminada. Rio de Janeiro: Record, 2001.

SOBRINHO, N. F. S. Desigualdade e Pobreza: fatos estilizados e simulações. Revista Paranaense de Desenvolvimento. Curitiba, oㅡ 100, p. 109-133, 2001.

SCHULTZ, T. W. Investindo no povo: o segredo econômico da qualidade da população. Rio de Janeiro: Forense Universitária, 1987.

(Recebido em 26.03.2014. Aceito em: 14.06.2014) 